\title{
Clinical analysis of related factor influencing the increase in body mass index after kidney transplantation
}

\author{
Hyo-Sin Kim¹, Yeon-Ho Han², Seok-Joon Sohn², Ho Kyun Lee', Soo Jin Na Choi ${ }^{1}$ \\ ${ }^{1}$ Department of Surgery, Chonnam National University Medical School, Gwangju, Korea \\ ${ }^{2}$ Department of Preventive Medicine, Chonnam National University Medical School, Gwangju, Korea
}

Background: Increased bodyweight after kidney transplantation lowers the quality of life and significantly reduces the survival rate of transplanted kidneys. The aim of the study was to evaluate factors related on body mass index (BMI) increase after kidney transplantation.

Methods: From 2014 to 2017, among the 110 patients who underwent kidney transplantation was selected. BMI was compared at 6 months, 1 year, and 2 years after surgery according to the postoperative period; 6 months, 1 year, and 2 years. Multivariate analysis was performed to identify factors related to changes in BMI after surgery.

Results: According to the elapsed time after surgery, the BMI increased to $22.5 \mathrm{~kg} / \mathrm{m}^{2}$ after 6 months, $22.8 \mathrm{~kg} / \mathrm{m}^{2}$ after 1 year, $23.1 \mathrm{~kg} / \mathrm{m}^{2}$ after 2 years $(P<0.001)$. The factor influencing the increase in BMI were female sex, level of low-density lipoprotein cholesterol, steroid use, and medication of statin.

Conclusions: To prevent an increase in BMI after kidney transplant, appropriate exercise and diet, medication for hyperlipidemia, and steroid tapering as soon as possible are required.

Corresponding author: Hyo-Sin Kim

E-mail: gideon0504@gmail.com

\section{(C) The Korean Society for Transplantation}

This is an Open Access article distributed under the terms of the Creative Commons Attribution Non-Commercial License (http://creativecommons.org/licenses/by-nc/4.0/) which permits unrestricted non-commercial use, distribution, and reproduction in any medium, provided the original work is properly cited. 